\title{
Practicing Mass Casualty Scenarios: Experience From a Developing Level 1 Trauma Center in the Himalayan Foothills
}

Md Quamar Azam, MS; Mahesh Devasthale, BSc; Chandu Raj B, MSc; Ajay Kumar, MS; Bhaskar Sarkar, MS; Amulya Rattan, MCh (1)

\section{ABSTRACT}

Objective: Uttarakhand is an Indian state in the Himalayan foothills, a favored adventure destination in the country due to abundant natural beauty. However, the terrain has also conferred an increased risk of earthquakes, flash floods, and major road tragedies, resulting in as many as 8 major natural disasters in the state in the preceding 20 years. AlIMS Rishikesh, an autonomous central institute, has been entrusted to build a Level 1 Trauma Center in Uttarakhand, which would help improve the response, coordination, and hence outcome in mass casualty scenarios (MCSs).

Methods: As a step toward the achievement of this larger goal, a workshop on MCS and management was conducted by the Department of Trauma Surgery in collaboration with Rambam Hospital, Haifa. We hereby present our template for conducting MCS drills in low resource settings like ours and the lessons learnt.

Results: Process, logistics, limitations, workforce, scheduling, overview, and report of the MCS drill conducted are discussed hereafter.

Conclusion: This template may be replicated by hospitals that intend to conduct similar MCS drills in low resource settings, realizing the real threat of MCS occurrence in our country at anytime.

Key Words: capacity building, disaster preparedness, drills, mass casualty scenarios, MCS preparedness

$\mathrm{M}$ ass casualty scenarios (MCSs) are manmade or natural events leading to injuries that overwhelm a given hospital's management capacity. ${ }^{1}$ A sudden surge of patients and space constraints are further compounded by lack of efficient triage, haphazard resource allocation, and paucity of trained health care providers. As a result, preventable deaths and long-term disabilities are much more when compared with routine management in the same hospitals. ${ }^{2}$ This highlights the need to orient and train health care providers in MCS management, especially in areas where MCSs have occurred in the past and remain a threat in the near future.

Uttarakhand is one of the most sought after pilgrimage and adventure destinations in the country. ${ }^{3}$ It's replete with natural resources and beauty, located in the Himalayan foothills; however, the same factors also confer an increased risk of earthquakes, flash floods, and major road tragedies. ${ }^{4}$ Supplementary Table 1 lists the major disasters in the state over the last 20 years.

All India Institute of Medical Sciences (AIIMS) Rishikesh is entrusted to build a Level 1 Trauma Center, which would help improve the response, coordination, and hence outcome in MCSs. Towards achievement of this endeavor, a workshop on MCSs and management was conducted by the Department of Trauma Surgery, AIIMS Rishikesh in collaboration with Rambam Hospital, Haifa, Israel in January 2019. Rambam Hospital is renowned world over for its disaster management expertise and is capable of shifting an 1100 bedded hospital to an underground fortified location with 72 hours of any threat declaration. ${ }^{5}$

A drill is a coordinated, supervised activity used to test a single specific operation or function in a hospital or other organization. ${ }^{6}$ Typical drills for hospitals include decontamination, fire evacuation, and power failure. Drills can also be used to provide training on new equipment, develop or test new policies or procedures, or practice and maintain current skills. ${ }^{6}$ For this type of exercise, hospitals typically choose to test their communication and notification systems and equipment.

We intend to present here our template for conducting MCS drills. Process, logistics, limitations, workforce, scheduling, overview, and report of the MCS drill conducted are discussed hereafter. This template may be 
replicated by hospitals that intend to conduct similar MCS drills, realizing the real threat of MCS occurrence in our country at anytime.

\section{METHODS \\ Schedule}

A 3-day MCS preparedness workshop was organized. The initial 2 days were allotted for expert talks and tabletop drills, which oriented participants to MCS management, vignettes, and practical issues. The drill was planned on the last day of the workshop.

\section{Place of Conduct}

It was carried out in areas actually designated for triage and initial management of the upcoming trauma center. This was done intentionally to test the robustness of the trauma center design and address the pitfalls in carrying out operations in an actual MCS.

\section{Participants}

In collaboration with Rambam faculty, a scenario was created about a stampede at Laxman Jhula, a popular and crowded tourist spot, $5 \mathrm{~km}$ from AIIMS. Thirty victims would be expected to arrive at AIIMS Trauma Center. The injury profile of patients was provided by Rambam faculty.

As mannequins for 30 patients would have involved a large cost, it was decided to instead use institute volunteers acting as moulage patients. Institute security personnel were approached, who agreed enthusiastically to play a part. Fifteen nurses and 6 doctors were delegated for 30 casualties, in accordance with staffing expected at our Emergency Department (ED) should a real MCS happen. All nurses were volunteers and had prior or current posting in the ED. Three senior nursing officers were delegated for the supervision of nursing care.

\section{Practice Run}

A trauma surgeon (Dr Rattan) was delegated the responsibility of preparations leading to the MCS drill. Ten days before the actual drill, 2 interactive sessions were organized on Primary Survey and Triage for all nurse participants to ensure baseline knowledge of $\mathrm{ABCDE}$ (doctors and nurses). The timing of sessions was decided by nursing officers themselves, ensuring minimal interference from routine work. This also encouraged a sense of active participation. Immediately after the sessions, a demonstration of model initial management and teamwork was done in traditional ATLS format (perform and critique by turns). It helped identify pitfalls, clarify doubts, and promote bonding (Figure 1A).

After the orientation of participants to Primary Survey and Initial Assessment, a practice run of the drill was conducted
7 days before the scheduled drill with 15 moulage patients (security guards) and 15 nurses. Areas for red, yellow, green, and triage bay were identified by Dr A. Two senior nursing officers did tasks of area labeling, moulage patient makeup, arranging trolleys for 30 patients, arranging medical equipment for all zones, making patient identifiers, arranging printed forms for primary survey, treatment charts, and color-coded wrist bands for triage. They were also supposed to manage the interval between the arrival of successive patients at the triage counter. Another senior nursing officer was made the nursing director for the drill to ensure judicious resource allocation and address nursing issues that would arise during practice. Six senior resident doctors were called and after a formal introduction to one another, trauma teams were created for the practice run (Supplementary Table 2). One person was delegated for video graphing practice drills in all areas.

Stretchers couldn't be arranged in adequate numbers, so stretcher recycling was done by senior nursing officers. Besides, wheelchairs and multiple patients on a single stretcher were brought in to simulate real-life scenarios. Acute collapse of some patients was enacted at the triage counter to generate panic reaction and monitor the response. The drill was planned for 15 patients; however, 30 patients were sent to evaluate the trauma team response. The triage team was expected to triage patients quickly, accurately, and keep the receiving area vacant for incoming patients using the Field Triage Decision Scheme. Respective trauma teams were expected to detect and document all life and limb-threatening injuries in patients received, interventions done or planned, and label patients for final disposition, that is, operating room (OR), intensive care unit (ICU), ward, or step down/ discharge. Senior nursing officers were supposed to look after resource redistribution in case of a crisis. The practice drill lasted 35 minutes. After stopping the drill, moulage patients were thanked and applauded and the group picture taken (see Figure 1B).

The medical and nursing team proceeded for debriefing, where videography was reviewed and each patient discussed with respect to triage accuracy, injuries detected, missed, treatment documented, timeline, and correct disposition. Dr Rattan ensured that the debriefing was nonjudgmental, informative, 2-way, and non-blaming. Awkward moments caught in video kept the atmosphere light and receptive. Triage accuracy was low, with frequent under triages. It was found that, whereas yellow and green teams did reasonably well, the red team could correctly manage only 4 out of 10 patients received (Supplementary Table 3). Lack of documentation most commonly occurred in the red area. Omission of antiepileptic in head injury (2) and cross medications (1) were the most glaring errors in the red area. Debriefing was concluded on a congratulatory and thanking note, as all members spared time apart from clinical work for the MCS drill. The total time consumed in the drill, windup, and debriefing was 3 hours. 
Photos From MCS Drill
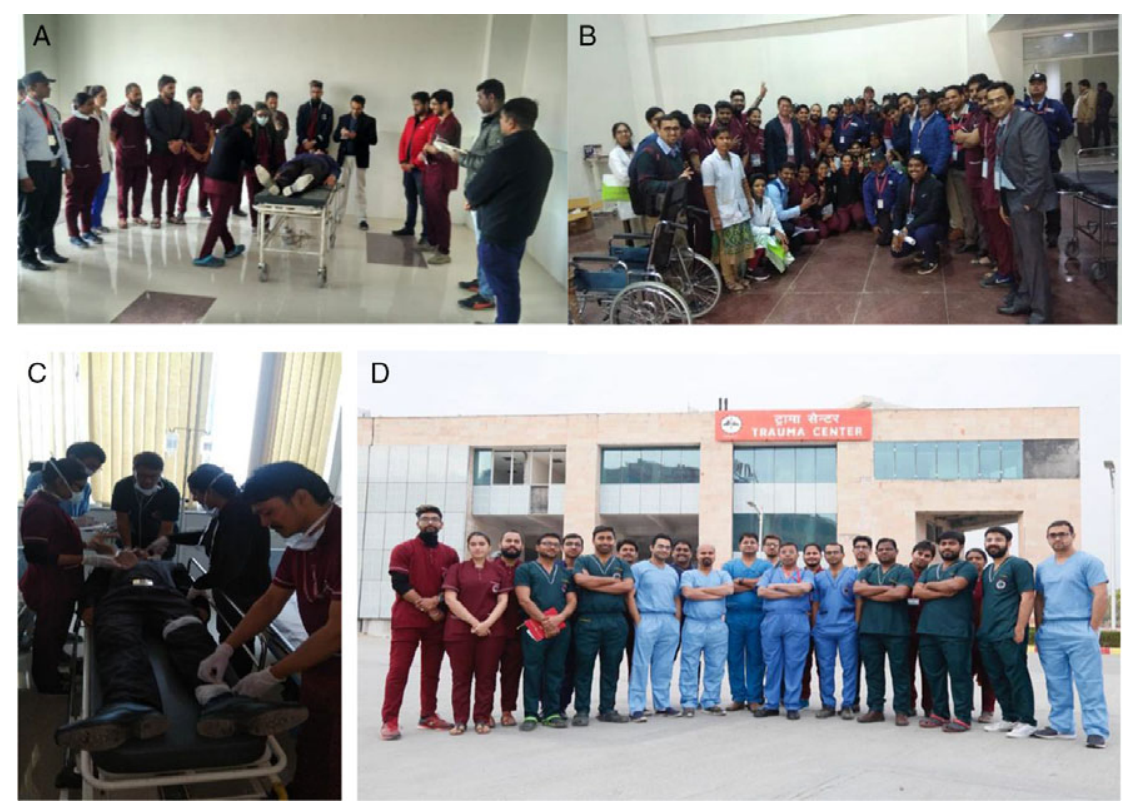

D

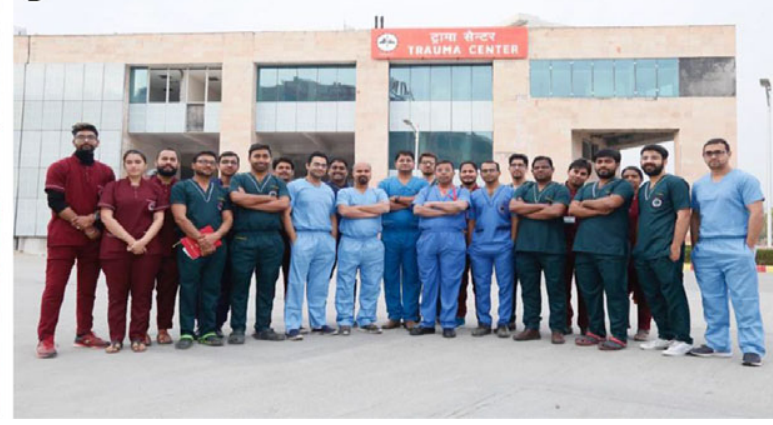

(A) Demonstration of model initial assessment and team work immediately after interactive sessions. (B) Applauding and thanking the volunteers.

(C) Actual MCS drill showing trauma team in action. (D) Trauma center staff.

\section{RESULTS}

\section{Actual MCS Drill}

On the morning of the scheduled MCS drill, 2 senior nursing officers arranged and confirmed all equipment, stretcher, site labeling, and stationary availability. Being Sunday morning, the arrangement of stretchers wasn't a problem as they could be mobilized from Out-Patient Department (OPD) areas.

Rambam faculty reviewed the drill site, arrangements, and tentative plan of the drill in the morning on the day of the drill. They emphasized the need for a counseling venue for non-injured but stressed patients, holding areas for patients waiting for beds in wards, and 1-way traffic from the red zone to minimize confusion. They also stressed upon the need of walkie-talkies, which, incidentally, were already procured by the institute. As per the current trauma center design, 1-way traffic couldn't be achieved completely; however, the guest faculty advised us against any last time changes. They reallocated areas in terms of triage, red, yellow, and green bays. The scenarios for individual patients were brought by guest faculty from Rambam Hospital, Israel. We are told that the scenarios are pretty constant and are used in any MCS drill mentored by Rambam faculty. A prototype scenario is shown in Figure 2.

One guest faculty planned the timing of patient arrival, another served as spot faculty, and third acted as an observer. Ventilators and crash carts weren't mobilized due to logistic issues. Makeup of moulage patients and consistency with injury profiles mentioned on cards were also cross-checked. Volunteer security guards in civil uniform were brought as moulage patients. Cards of individual patients included age, gender, medical/physical status, vital signs, and injuries. Makeup simulating similar injuries was done by 4 nursing officers. Moulages were briefed about their condition to enact as victims.

Six doctors took part in the drill. One trauma surgeon other than Dr Rattan was given the role of a medical director, and the nursing superintendent of the institute played the role of the nursing director. In addition, area in-charges for all zones were designated by guest faculty. Dr Rattan, the trauma surgeon in charge of preparations of the MCS drill, refrained from active participation to gauge the degree of training efficacy while working under unfamiliar leadership. Videography was done (see Figure 1C).

As the drill began with the approval of the medical director, many pitfalls were noted, including direct transfer of patients to the red zone by attendants bypassing the triage and unauthorized people entering the ED. Realizing the mistake, 2 senior nurse officers were appointed as security guards at the last moment for controlling human traffic.

After 20 minutes, Rambam faculty started rounds of ED and evaluating patients. One faculty member sent unauthorized people simulating media personnel inside, who gained access 


\section{Moulage Patients' Profile}

\section{Identifier: A8}

Short height female; Blue \& Yellow dress

\section{Prehospital info}

30 year female

Walking, Fully conscious

C/C:

Abrasion on head; Constantly talking about what happened

Tachycardia present but volume of pulse good; No external signs of injury

A Bit confused

\section{In hospital vitals:}

Pulse 100/min BP $133 / 84 \mathrm{mmHg}$

GCS 15 RR $26 / \mathrm{min} \quad$ Sat $94 \%$

\section{Examination}

Trachea central

Breath and heart sounds normal

Abdomen soft

No lateralizing signs

No long bone fracture

\section{Identifier: A9}

Young male; well built; white shirt and black pants

\section{Prehospital info}

22 year male

Brought on stretcher; vomiting; semi conscious

C/C:

Frontal scalp hematoma;

Shirt soaked with vomitus and blood Belligerent

\section{In hospital vitals:}

Pulse 120/min

GCS E1V3M5

BP $96 / 60 \mathrm{mmHg}$

Sat $84 \%$

RR $26 /$ min

\section{Examination}

Trachea central

Obstructed and laboured breathing

Abdomen soft

No external hemorrhage

\section{Take-Home Points From Debriefing}

\section{Positive Points}

1. Good team work

2. Every team member aware of job responsibility

3. $A B C$ Assessment at triage in 3.5 seconds

4. Communication between triage officer and medical director at regular interval

5. Patient shifted to/out of red area with information to area in charges

6. Appropriate documentation

7. Seriousness of drill

\section{Potential Areas of Improvement}

1. No closed loop communication from area in charges

2. No previous discussion regarding planning of areas

3. No control over media personnel

4. Brought dead patient shifted to red area which can be sent to black

5. No doctor in charge in red area

6. No closed loop communication in red area

7. No policy to vacate ED/red area

8. Lack of attendant/security guards in yellow area

9. No information to green in charge when patient down triaged from red

10. Patient's attendant entering working area and making chaos

11. Triage officer should be in triage area at all times, who left place frequently

12. Positioning of equipment/medicine should be easy to reach

13. Patient shifted too many times from trolley to bed to trolley

14. No lines drawn on floor showing different areas, red, yellow, green, imaging

15. Provision of oxygen/suction in vacant areas for use during MCS

16. Patient kept awaited in imaging/holding area for long

17. Position/designation tag should be worn by all team members for easy identification

18. Checklist at the exit of every area to assess necessary things done to maintain 1 way of efficient traffic

19. More departments such as OR, blood bank in future drills 


\section{TABLE 2}

\begin{tabular}{|ll|}
\hline \multicolumn{2}{|l|}{ Synopsis of Resources Consumed } \\
Human & \\
Doctors & 8 \\
Nurses & 20 \\
Volunteers & 30 \\
Time Consumed & \\
Planning & 8 hours \\
Theoretical session & 2 hours \\
Demonstration & 2 hours \\
Practice run & 3 hours \\
Drill & 3 hours \\
Logistics & \\
Space & \\
Drill & $40 \mathrm{ft}$ * 40 -ft space \\
Classroom, debriefing, & Faculty room \\
video review & \\
- Paper & Initial assessment sheets: 50 \\
& Labeling:10 \\
- Makeup & Color-coding wristbands: 50 \\
- Trolleys & Arranged by collective effort \\
- Equipment & $25:$ Mobilized from other locations \\
Tapes & in hospital (Sunday) \\
ET tubes & \\
Splints & 1 \\
Bandages & 20 (sealed; not opened) \\
Oxygen masks & 20 \\
IV sets & 50 \\
IV fluids & 50 \\
& 50 \\
\hline
\end{tabular}

easily and created chaos. Few people were sent into the ED as patients' relatives for creating ruckus, which again could happen easily due to a lack of dedicated and strict guards on the ED gate. Rambam faculty took rounds of each nook and corner and took stock of each and every patient received.

After 30 minutes and receiving 24 patients, the drill was stopped, volunteers thanked, and participants proceeded for a debriefing session.

Videography of the MCS drill was reviewed at the debriefing session. Volunteer security guards were presented certificates of appreciation and nurses applauded for their enthusiastic participation. Rambam faculty provided their invaluable feedback and important tips in the debriefing session, which is summarized in Table 1.

\section{DISCUSSION}

Mass casualty occurrences are a real threat everywhere, and more so in countries afflicted with terrorism, like India. The most impactful intervention in disaster medicine is to prevent an occurrence in the first place. ${ }^{7}$ However, it requires interdisciplinary coordination across various agencies and a certain baseline level of public education. In our setup, mitigating the effects of disasters when they occur is the second best and more practical option due to difficulties in interagency coordination. ${ }^{8}$ Therefore, the medical community has the greatest role in minimizing loss of life in such events.

Published literature proves beyond doubt that unpreparedness and ineffective leadership are the most common causes of preventable deaths in any MCS. ${ }^{9,10}$ Therefore, the need of the hour is to strengthen preparedness and establish pre-emptive leadership if a disaster occurs. Preparedness and prior drills lead to better composure, conduct, and productivity of human resources in an MCS. ${ }^{11}$ Hence, conducting an MCS drill is as important for a hospital as is having a disaster action plan in place.

Drills attempt to recreate real-life situations. Though simulation may not be completely successful at it, pitfalls in the processes can be certainly highlighted. Involvement of senior officers may ensure flawless conduct of exercise, but, in an actual MCS, this may not be the case and therefore frequent practices are necessary to identify bottlenecks and minimize preventable deaths and lapses. ${ }^{12}$

\section{Limitations}

Transport of victims from scene to hospital, involvement of the blood bank, OR, and ICU and dispatching of the mobile disaster response team were desirable components of the MCS drill that we couldn't execute due to logistic limitations.

\section{CONCLUSION}

We have shared here our template of organizing an MCS drill for disaster preparedness. Lessons learned in the process are (1) Accurate triage is the spine of efficient MCS management; (2) Under-documentation and mismanagement are most likely to occur in the red area. Pitfalls and bottlenecks of MCS management would manifest during actual drills only; and (3) Resources and infrastructure required for organizing an MCS drill are not substantial (Table 2).

\section{About the Authors}

Department of Trauma Surgery and Critical Care, Trauma Center, AIIMS Rishikesh, Uttarakhand 249203, India (Azam, Devasthale, Raj B, Kumar, Sarkar).

Correspondence and reprint requests to Amulya Rattan, Department of Trauma Surgery and Critical Care, Trauma Center, AIIMS, Rishikesh, Uttarakhand, India 249203 (e-mail: amulya.rattan@gmail.com).

\section{Acknowledgments}

The Department of Trauma Surgery (AIIMS Rishikesh) staff are thankful to their visionary Director-Professor Ravi Kant, who conceived this idea and provided all human and material resources for a successful workshop.

\section{Conflict of Interest Statement}

The authors have no conflicts of interest to declare. 


\section{Supplementary material}

To view supplementary material for this article, please visit https://doi.org/10.1017/dmp.2020.38

\section{REFERENCES}

1. Falcone R, Detty A, Augustine J. Man-made disaster: in-hospital management. Published November 1, 2015. https://www.reliasmedia.com/articles/ 136446-man-made-disaster-in-hospital-management. Accessed July 27, 2019.

2. Kuschner WG, Pollard JB, Ezeji-Okoye SC. Ethical triage and scarce resource allocation during public health emergencies: tenets and procedures. Hosp Topics. 2007;85(3):16-25.

3. Kaur J. Problems and prospects of ecotourism development in Kumaon region of Uttrakhand. Published April 9, 2016. http://shodhganga. inflibnet.ac.in/bitstream/10603/206965/12/final.pdf. Accessed July 27, 2019.

4. Shrivastava S, Shrivastava P, Ramasamy J. Disaster management: fallacies and solutions: an Indian perspective. Ann Med Health Sci Res. 2013;3(3):468-469. doi:10.4103/2141-9248.117940.
5. Sammy Ofer Fortified Underground Emergency Hospital. https://www. rambam.org.il/en/. Accessed July 27, 2019.

6. Drills: definition. https://txssc.txstate.edu/tools/tde-toolkit/exercising. Accessed July 27, 2019.

7. Norton J, Gibson TD. Introduction to disaster prevention: doing it differently by rethinking the nature of knowledge and learning. Disaster Prev Manage Int J. 2019;28(1):2-5.

8. Nath S. A sociological perspective on "institutional coordination" for disaster risk reduction in India. In: Disaster Risk Reduction. Singapore: Palgrave Macmillan; 2019:157-172.

9. Karampourian A, Ghomian Z, Khorasani-Zavareh D. Qualitative study of health system preparedness for traumatic incidents in a religious mass gathering. Injury. 2019;50(5):1097-1104.

10. Ozoilo KN, Pam IC, Yiltok SJ, et al. Challenges of the management of mass casualty: lessons learned from the Jos crisis of 2001. World J Emerg Surg. 2013;8(1):44.

11. Kapucu N. Collaborative emergency management: better community organizing, better public preparedness, and response. Disasters. 2008;32(2): 239-262.

12. Ford JK, Schmidt AM. Emergency response training: strategies for enhancing real-world performance. J Hazard Mater. 2000;75(2-3):195-215. 